\title{
Susceptibility to Aneuploidy in Young Mothers of Down Syndrome Children
}

\author{
Lucia Migliore $^{1, \star}$, Francesca Migheli ${ }^{1}$, and Fabio Coppedè ${ }^{2}$ \\ ${ }^{1}$ Department of Human and Environmental Sciences and ${ }^{2}$ Department of \\ Neuroscience, University of Pisa, Italy \\ E-mail: I.migliore@geog.unipi.it
}

Received May 6, 2009; Revised September 9, 2009; Accepted September 21, 2009; Published October 2, 2009

\begin{abstract}
We recently observed an increased frequency of binucleated micronucleated lymphocytes in women who had a Down syndrome (DS) child before 35 years of age and the fluorescence in situ hybridization analysis revealed that micronuclei were mainly originating from chromosomal malsegregation events, including chromosome 21 malsegregation. That study indicated that women who have a DS child at a young age might have a genetic predisposition to chromosome malsegregation in both somatic and germ line cells. Further studies from our group confirmed increased chromosome damage in blood cells of women who had a DS child at a young age and pointed to a possible role for polymorphisms in folate-metabolizing genes in affecting both chromosome damage and DS risk. In the present article, we review the most recent findings on mechanisms and risk factors for chromosome 21 nondisjunction that lead to DS. Multiple risk factors are likely involved in chromosome nondisjunction; they act at different times in the meiotic process and can be of genetic or environmental (epigenetic) origin. We also discuss the increased risk of developing Alzheimer's disease (AD) later in life that was observed in women who had a DS child at a young age. Studies performed in the last years that have shown that the brain is, in fact, a complex genetic mosaic of aneuploid and euploid cells support the unified hypothesis trying to relate DS, trisomy 21, and AD.
\end{abstract}

KEYWORDS: Down syndrome (DS), mothers of Down syndrome children, trisomy 21, folate metabolism, epigenetics, Alzheimer's disease (AD), risk factors

\section{INTRODUCTION}

Down syndrome (DS) or trisomy 21 (MIM 190685) is a genetic disease resulting from the presence and the expression of three copies of genes located on chromosome 21. Since the discovery of Lejeune et al.[1], the phenotype of DS has been associated with trisomy for chromosome 21 (or, in some cases, of a large portion of $21 \mathrm{q}$ denoted as the DS critical region).

Primary trisomy 21 leading to DS is caused by the failure of a normal chromosome 21 segregation during meiosis (meiotic nondisjunction) and accounts for $92 \%$ of the total of DS cases[2]. In 95\% of the cases, primary trisomy 21 is of maternal origin, with the nondisjunction event occurring primarily during meiosis I (MI) in the maturing oocyte, before conception. In contrast, paternal nondisjunction of 
chromosome 21 during spermatogenesis only accounts for 5\% of the cases[3]. Only 5\% of the total of DS cases is due to Robertsonian translocations of $21 \mathrm{q}$ in one of the parents, the most common being $\mathrm{t}(14 \mathrm{q} ; 21 \mathrm{q})$, resulting in 21q trisomy in the offspring[4]. Furthermore, there is indication that $\mathrm{t}(14 \mathrm{q} ; 21 \mathrm{q})$ occurs primarily during oogenesis[5]. The remaining $3 \%$ of DS is due to mosaicism, resulting from errors occurring during the first divisions of the zygote[3]. Individuals with primary trisomy 21 possess three copies of the entire chromosome 21, cases due to Robertsonian translocations have a partial (21q) trisomy, whereas mosaics have both normal and trisomic cells, and the DS phenotype varies as a function of the percentage of trisomic cells present in different tissues[6].

The molecular mechanisms underlying meiotic nondisjunction leading to trisomy 21 are still poorly understood and the major risk factor for trisomy 21 is advanced maternal age at conception[3], while paternal age seems to be insignificant in the etiology of DS[7]. After age 35, the risk of bearing a child with DS increases substantially with increasing maternal age; however, most mothers of DS individuals (MDS) are 35 years or younger, suggesting a genetic susceptibility to early nondisjunction for chromosome 21 in such women[8].

\section{THE ORIGIN OF MATERNAL CHROMOSOME 21 NONDISJUNCTION}

Given the strong correlation between advanced maternal age at conception and increased risk for having a DS child, it was believed that chromosome 21 nondisjunction could be the result of the age-related accumulation of errors that makes the female meiotic machinery less efficient and more error prone. However, despite evidence that advanced maternal age at conception is the major risk factor for trisomy 21 , little is still known about the molecular mechanisms responsible for chromosome 21 nondisjunction.

Several studies have related altered levels and positioning of meiotic recombinational events to human nondisjunction. Particularly, studies of trisomy 21 have shown that altered levels or absence of recombination are associated with maternal nondisjunction occurring at both meiosis I (MI) and meiosis II (MII). It was observed that nearly one-half of MI errors are caused by the absence of chromosome 21 recombination during maternal meiosis, whereas the majority of the remaining MI errors had recombination events that clustered at the telomere. In contrast, nondisjunction events due to errors at maternal MII were associated with recombination that clustered at the pericentromeric region of the chromosome, suggesting that all nondisjunction events may be initiated during MI and simply resolved at either of the two meiotic stages[9,10].

Subsequent studies have been performed to search for a possible association between maternal age and altered chromosome 21 recombination patterns. A study of trisomy 21 cases of maternal MI origin, grouped by maternal age, indicated that, effectively in aged women, chromosome 21 nondisjunction could be caused by the age-related accumulation of errors leading to a less-efficient meiotic machinery more prone to chromosomal malsegregation. On the contrary, the absence or the altered placement of recombination during MI is likely to be the cause of chromosome 21 nondisjunction in young women[11]. Further confirmation comes from the observation that, for maternal MI errors, a single telomeric exchange imposes the same risk for nondisjunction, irrespective of the age of the oocyte[12]. On the contrary, the examination of MII errors indicates that the presence of a single exchange within the pericentromeric region of $21 \mathrm{q}$ interacts with maternal age-related risk factors[12]. A recent large casecontrol study provided the following findings: (a) advanced maternal age was significantly associated with both MI and MII errors, and (b) the ratio of MI to MII errors differed by maternal age. The ratio was lower among women $<19$ years of age and those $\geq 40$ years and higher in the middle-age group[7].

A recent hypothesis suggested that maternal trisomy 21 ovarian mosaicism might be another mechanism leading to DS. The authors analyzed premeiotic ovarian cells obtained from eight phenotypically normal female fetuses, observing trisomy 21 mosaicism in all individuals. Therefore, the authors suggested that disomy 21 in eggs could originate from altered pairing and nondisjunction of chromosome 21 during the meiosis of trisomic ovarian cells, indicating that such a phenomenon could also explain the observed altered recombination patterns of chromosome 21 during meiosis[13]. 


\section{FOLATE METABOLISM AND DOWN SYNDROME RISK}

Folate metabolism is required for the synthesis of the major DNA-methylating agent Sadenosylmethionine (SAM) (Fig. 1). It is now known that in mice, maternal methyl donor supplementation during gestation can alter the offspring phenotype by methylating specific CpG islands[14]. However, 10 years ago, it was suggested that impaired folate metabolism, resulting from the presence of a functional polymorphism of the methylenetetrahydrofolate reductase gene (MTHFR), might be a maternal risk factor for having a DS infant[15]. The hypothesis was that a stable centromeric DNA chromatin might depend on the epigenetic inheritance of specific centromeric methylation patterns and on the binding of specific methyl-sensitive proteins in order to maintain the higher-order DNA architecture necessary for kinetochore assembly. Therefore, it was suggested that pericentromeric hypomethylation, resulting from inadequate folate intake and/or impaired folate metabolism, could impair the formation of the kinetochore, resulting in chromosomal nondisjunction[15].

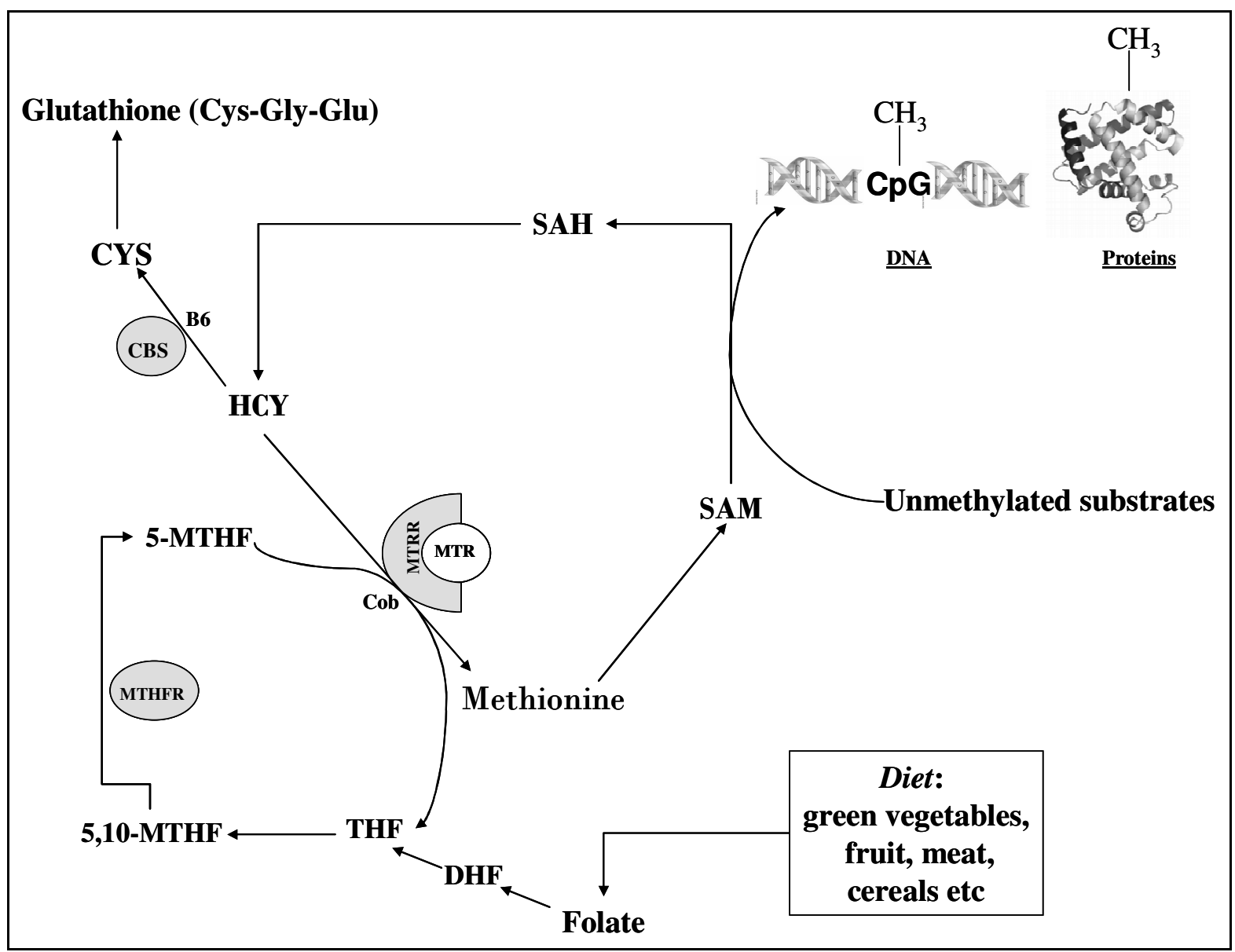

FIGURE 1. Folate metabolic pathway. B6, vitamin B6; CBS, cystathionine- $\beta$-synthase; Cob, vitamin B12; CYS, cysteine; DHF, dihydrofolate; Glu, glutamic acid; Gly, glycine; HCY, homocysteine; 5-MTHF, 5-methyltetrahydrofolate; 5,10-MTHF, 5,10methyltetrahydrofolate; MTHFR, methylenetetrahydrofolate reductase; MTR, methionine syntase; MTRR, methionine syntase reductase; SAH, S-adenosylhomocysteine; SAM, S-adenosylmethionine; THF, tetrahydrofolate.

However, as discussed in a previous paragraph, recent evidence suggests that the absence or the altered placement of chromosome 21 recombination during maternal meiosis is responsible for nondisjunction. Therefore, the question is whether or not there could be a link between folate metabolism 
and chromosomal recombination. Several studies provided evidence that DNA methylation at CpG sites is a mechanism that serves to suppress recombination, providing a direct link between recombination, epigenetic processes, and folate metabolism[16,17]. Particularly, it is clear that crossovers are not randomly distributed, but clustered at specific regions. It has been proposed that DNA methylation might prevent crossover formation, therefore regulating chromosome recombination[16].

Paternal nondisjunction of chromosome 21 during spermatogenesis is the cause of less than 5\% of the total of DS cases. Recent studies linked a reduced dietary intake of folate with increased frequency of aneuploidy in spermatozoa, including chromosome 21 disomy[18]. Moreover, there is indication that nonobstructive infertility in males is caused by the absence or the altered position of chromosomal recombination during meiosis[19], and associated with polymorphisms in folate-metabolizing genes[20].

Studies performed on cultured human cells demonstrated that folate deprivation is able to induce chromosome 21 aneuploidy[21], thus linking aberrant folate metabolism to the hypothesis that some DS cases could originate from maternal mosaicism.

Several studies were performed in the last years that were aimed at clarifying the possible role of impaired folate metabolism to DS risk; however, the question is still debated and none of the studied polymorphisms of metabolic genes can be considered undoubtedly as an independent DS risk factor, whereas there is increasing evidence that combinations of two or more of them might affect the risk for a DS pregnancy[22,23,24,25,26,27]. Complex interactions between genetic (metabolic polymorphisms) and environmental factors (folates and related nutrients) have also been suggested[28]. Particularly, most of chromosome 21 nondisjunction events initiate at maternal MI during maternal embryogenesis in the grandmother's body, pointing to a possible role for the maternal grandmother's diet in DS risk[27,29]. Moreover, several of the genes located on chromosome 21 participate in folate metabolism and are overexpressed in DS individuals, possibly resulting in increased folate demand and/or availability in developing DS fetuses, and suggesting that complex interactions between the maternal folate intake during gestation and the trisomic fetal genotype might be relevant for the fetus to develop and survive up to the birth[28].

We obtained similar indications (i.e., gene-gene interactions between MTHFR and other genes participating in folate metabolism) when analyzing seven different polymorphisms in folate metabolic genes as possible risk factors for having a DS child at a young ( $<35$ years) maternal age. A first report by us suggested that combinations of MTHFR gene polymorphisms with the $80 \mathrm{G}>\mathrm{A}$ polymorphism in the reduced folate carrier gene ( $R F C 1)$ might impair DS risk[24]. That study is of particular interest since similar or complementary indications came from subsequent independent studies performed by other research groups[26,30]. More recently, we suggested interactions between MTHFR variants with other genes of the folate pathway, namely thymidilate synthase (TYMS) and methionine synthase (MTR), as possible DS risk factors at a young maternal age[27]. This study, recently published, is pending replication in other populations.

Moreover, studies performed in other human aneuploidies than trisomy 21 indicate association of the MTHFR 1298A $>$ C polymorphism with Turner syndrome[31] and the MTHFR $677 \mathrm{C}>\mathrm{T}$ polymorphism with trisomy $18[32]$.

\section{CYTOGENETIC FINDINGS IN YOUNG MOTHERS OF DOWN SYNDROME CHILDREN}

We performed a study aimed at evaluating cytogenetic characteristics, through the micronucleus test, of peripheral blood lymphocytes of a group of women who had a DS child at a young age, in comparison with a control group of mothers who had a healthy child. Moreover, we evaluated the presence of any susceptibility to malsegregation events in a subgroup of mothers by applying the fluorescence in situ hybridization (FISH) with molecular probes for chromosomes 13 and 21. A significant increased frequency of binucleated cells with micronuclei was observed. By using probes for chromosomes 13 and 21, the FISH revealed that micronuclei mainly originated from malsegregation events, rather than from 
chromosome breakage[33]. The study suggested that young MDS might have a generalized tendency to chromosome malsegregation events, not limited to gametes, but detectable even in somatic cells, which could be partially determined by genetic factors.

To further address this question, we subsequently increased the number of MDS under study and searched for a possible correlation between polymorphisms in several folate-related genes and the frequency of binucleated micronucleated lymphocytes (BNML). Those studies confirmed our previous observation of an increased frequency of BNML in MDS respective to controls, and pointed to an association between MTHFR gene polymorphisms, namely $677 \mathrm{C}>\mathrm{T}$ and $1298 \mathrm{~A}>\mathrm{C}$, and the frequency of BNML in both MDS and controls. However, it also emerged that the MTHFR locus alone cannot account for the overall observed increased chromosomal damage in MDS respective to control mothers, suggesting a polygenic contribution in addition to that of still-unclear environmental factors[27,34].

\section{YOUNG MOTHERS OF DOWN SYNDROME CHILDREN AND ALZHEIMER'S DISEASE RISK}

There is a link between DS and Alzheimer's disease (AD). The evidence is that by the fourth decade of life, individuals with DS inevitably develop many of the neuropathological features found in AD and the majority of these individuals develop dementia[35]. The hypothesis is that constitutive trisomy 21 can have a role in brain dysfunction, likely due to the overexpression of genes mapping to chromosome 21, in particular that coding for amyloid precursor protein (APP; senile extracellular plaques are composed of beta-amyloid peptides derived from proteolytic processing of APP).

Among individuals prone to undergo AD are mothers who had a DS child at a young age; an increased frequency of AD (about fivefold) among young MDS is reported[8,36]. A unifying hypothesis trying to relate DS, trisomy 21, and AD was developed in 1991 by Potter[37]. He proposed that trisomy 21 mosaicism at germ cell level or in brain cells could account for the familial aggregation of AD and DS[37].

Studies performed in the last years have shown that the brain is, in fact, a complex genetic mosaic of aneuploid and euploid cells[38]. The possible function of neural aneuploidy and mosaicism could include contributions to cellular diversity, cellular signaling, and diseases of the central nervous system[38]. Aneuploidy in the cerebral cortex of normal and $\mathrm{AD}$ brains was recently confirmed by molecular cytogenetic approaches, using DNA probes for different chromosomes, including chromosome 21. The overall proportion of aneuploid cells in the normal brain has been estimated at approximately $10 \%$. Compared with sex- and age-matched controls, the level of stochastic aneuploidy in the AD brain was not found to be significantly increased. However, a dramatic 10-fold increase of chromosome 21-specific aneuploidy was detected in the AD cerebral cortex[39]. Mosaicism for trisomy 21 in brain cells could thus, according to Potter's hypothesis, be critical for AD development; a case of young-onset AD due to occult mosaicism for trisomy $21(10 \%)$ was indeed reported in a patient with no previous diagnosis of DS and only minimal physical manifestations of DS[40]. Somatic mosaicism of cells euploid, but with a mutation in a gene critical for the familial forms of $\mathrm{AD}$ (inherited as an autosomal-dominant trait), was reported in a sporadic early-onset patient with AD. He resulted as a somatic mosaic for a mutation in the presenilin-1 gene and the degree of mosaicism was at $8 \%$ in peripheral lymphocytes and $14 \%$ in the cerebral cortex[41].

Indeed, genomic (chromosomal) instability was shown in other tissues than the brain of AD patients. An increased level of chromosome 21 aneuploidy was observed in lymphocytes, fibroblasts, and buccal mucosa cells of AD patients[42,43,44,45]. To these findings, we can juxtapose our data obtained in lymphocytes of MDS, which were found more prone to nondisjunction events for chromosomes 13 and 21[33]. The hypothesis we suggested in that paper was that those mothers are thus more prone to chromosome malsegregation, and it could be true both for somatic (peripheral blood lymphocytes, brain) as well as for germ cells. 
Finally, we would like to mention the fundamental finding that neurons, believed until a decade ago to be in a terminally differentiated postmitotic quiescent state, can re-enter the cell division cycle. Specifically in $\mathrm{AD}$, susceptible neurons exhibit phenotypic changes characteristic of cells re-entering the cell division cycle. Even if it is a relatively rare event, the re-entry into a coordinated cell cycle culminates in nuclear division[46]. It has been demonstrated that various mitogenic signals can cause cell cycle re-entry of neurons in the central nervous system of AD patients, such as loss of synaptic connections and levels of plasma homocysteine (Hcy)[47]. An interesting recent hypothesis predicted that cell cycle re-entry in AD is highly regulated by centromere cohesion dynamics[47]. The sequential separation and segregation of centromeres in the metaphase-anaphase transition is genetically controlled and it has been shown that this sequence of temporal order is altered in $\mathrm{AD}$, i.e., centromeres divide prematurely. This aberrant division is called premature chromosome separation and is seen as a manifestation of genome instability; it has been found in aging, in other chromosome instability syndromes, and in vitro following certain chemical treatments, as well as in $\mathrm{AD}[48,49]$. At present there is agreement about the fact that aneuploidy and enhanced neurogenesis are hallmarks of the pathology of $\mathrm{AD}[50]$. The confirmation that neurogenesis occurs in the adult brain and neural stem cells in the adult central nervous system also suggests interesting consequences, such as that the brain may be amenable to repair[51].

In view of the important role of folate metabolism already elucidated above, and considering that $\mathrm{AD}$ is characterized by high Hcy and low folate blood levels, meaning that the conversion of Hcy to methionine is altered, as is the production of SAM[52,53], it is likely that an impaired folate metabolism might contribute to the genomic instability observed in AD individuals. A deregulation of a proper chromosome segregation could be the initial event that leads to a clear manifestation of chromosome instability (aneuploidy, binucleation), which may contribute to neuronal degeneration and subsequent cognitive deficits in AD.

\section{CONCLUDING REMARKS}

Overall, the birth of a DS child seems to result from genetic (i.e., polygenic contribution of maternal and fetal folate-metabolizing genes and chromosomal mutations, meiotic chromosome pairing, recombination, or the detection of errors in these processes) and environmental factors (maternal age, maternal and maternal grandmother diet at pregnancy), as well as epigenetic (DNA methylation) and stochastic events (age-related accumulation of damages to biological components participating in chromosomal segregation). Therefore, further studies are required in order to understand the single contribution of each of them. In the light of an interesting point of view that describes human nondisjunction likely as a multifactorial trait[12], even if we are still far from the understanding of the basis of the susceptibility to aneuploidy of MDS, we can outline the scenario shown in Fig. 2. 


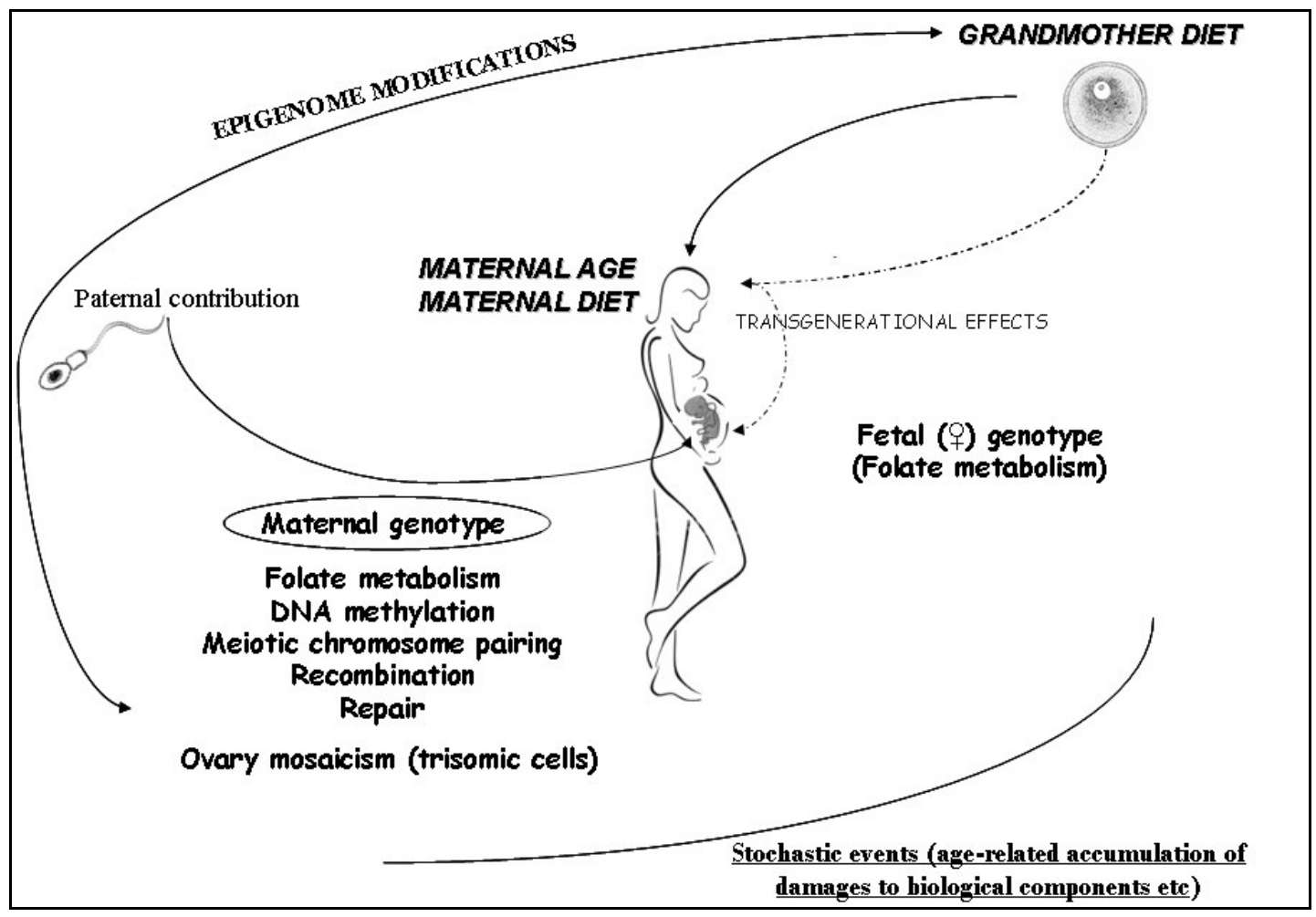

FIGURE 2. The human nondisjunction is a complex trait[12] likely due to an interaction between environmental factors and genetic predisposition. In MDS children only few risk factors have been identified so far.

\section{REFERENCES}

1. Lejeune, J., Gautier, M., and Turpin, R. (1959) Etude des chromosomes somatiqaues de neuf enfants mongoliens. $C$. R. Acad. Sci. 248, 1721-1722.

2. $\quad$ Epstein, C.J. (1995) Down syndrome (trisomy 21). In The Metabolic and Molecular Bases of Inherited Disease. 7th ed. Stansbury, J.B., Wyngarden, J.B., and Fredrickson, D.S., Eds. McGraw-Hill, New York. pp 749-795.

3. Antonarakis, S.E. (1998) Down syndrome. In Principles of Molecular Medicine. Jameson, J.L., Ed. Humana Press, Totowa, N.J. pp. 1069-1078.

4. $\quad$ Berend, S.A., Page, S.L., Atkinson, W., McCaskill, C., Lamb, N.E., Sherman, S.L., and Shaffer, L.G. (2003) Obligate short-arm exchange in de novo Robertsonian translocation formation influences placement of crossovers in chromosome 21 nondisjunction. Am. J. Hum. Genet. 72, 488-495.

5. $\quad$ Bandyopadhyay, R., Heller, A., Knox-DuBois, C., McCaskill, C., Berend, S.A., Page, S.L., and Shaffer, L.G. (2002) Parental origin and timing of de novo Robertsonian translocation formation. Am. J. Hum. Genet. 71, 1456-1462.

6. Papavassiliou, P., York, T.P., Gursoy, N., Hill, G., Nicely, L.V., Sundaram, U., McClain, A., Aggen, S.H., Eaves, L., Riley, B., and Jackson-Cook, C. (2009) The phenotype of persons having mosaicism for trisomy 21/Down syndrome reflects the percentage of trisomic cells present in different tissues. Am. J. Med. Genet. A 149, 573-583.

7. Allen, E.G., Freeman, S.B., Druschel, C., Hobbs, C.A., O'Leary, L.A., Romitti, P.A., Royle, M.H., Torfs, C.P., and Sherman, S.L. (2009) Maternal age and risk for trisomy 21 assessed by the origin of chromosome nondisjunction: a report from the Atlanta and National Down Syndrome Projects. Hum. Genet. 125, 41-52.

8. Schupf, N., Kapell, D., Lee, J.H., Ottman, R., and Mayeux, R. (1994) Increased risk of Alzheimer's disease in mothers of adults with Down's syndrome. Lancet 344, 353-356.

9. Lamb, N.E., Freeman, S.B., Savage-Austin, A., Pettay, D., Taft, L., Hersey, J., Gu, Y., Shen, J., Saker, D., May, K.M., Avramopoulos, D., Petersen, M.B., Hallberg, A., Mikkelsen, M., Hassold, T.J., and Sherman., S.L. (1996) Susceptible chiasmate configurations of chromosome 21 predispose to non-disjunction in both maternal meiosis I and meiosis II. Nat. Genet. 14, 400-405.

10. Lamb, N.E., Feingold, E., and Sherman, S.L. (1997) Estimating meiotic exchange patterns from recombination data: an application to humans. Genetics 146, 1011-1017.

11. Lamb, N.E., Yu, K., Shaffer, J., Feingold, E., and Sherman, S.L. (2005) Association between maternal age and meiotic recombination for trisomy 21. Am. J. Hum. Genet. 76, 91-99. 
12. Oliver, T.R., Feingold, E., Yu, K., Cheung, V., Tinker, S., Yadav-Shah, M., Masse, N., and Sherman, S.L. (2008) New insights into human nondisjunction of chromosome 21 in oocytes. PLoS Genet. 4e1000033.

13. Hultén, M.A., Patel, S.D., Tankimanova, M., Westgren, M., Papadogiannakis, N., Jonsson, A.M., and Iwarsson, E. (2008) On the origin of trisomy 21 Down syndrome. Mol. Cytogenet. 1, 21.

14. Waterland, R.A. and Jirtle, R.L. (2003) Transposable elements: targets for early nutritional effects on epigenetic gene regulation. Mol. Cell. Biol. 23, 5293-5300.

15. James, S.J., Pogribna, M., Pogribny, I.P., Melnyk, S., Hine, R.J., Gibson, J.B., Yi, P., Tafoya, D.L., Swenson, D.H., Wilson, V.L., and Gaylor, D.W. (1999) Abnormal folate metabolism and mutation in the methylenetetrahydrofolate reductase gene may be maternal risk factors for Down syndrome. Am. J. Clin. Nutr. 70, 495-501.

16. Buard, J. and de Massy, B. (2007) Playing hide and seek with mammalian meiotic crossover hotspots. Trends Genet. 23, 301-309.

17. Lees-Murdock, D.J. and Walsh, C.P. (2008) DNA methylation reprogramming in the germ line. Epigenetics 3, 5-13.

18. Young, S.S., Eskenazi, B., Marchetti, F.M., Block, G., and Wyrobek, A.J. (2008) The association of folate, zinc and antioxidant intake with sperm aneuploidy in healthy non-smoking men. Hum. Reprod. 23, 1014-1022.

19. Ferguson, K.A., Wong, E.C., Chow, V., Nigro, M., and Ma, S. (2007) Abnormal meiotic recombination in infertile men and its association with sperm aneuploidy. Hum. Mol. Genet. 16, 2870-2879.

20. Lee, H.C., Jeong, Y.M., Lee, S.H., Cha, K.Y., Song, S.H., Kim, N.K., Lee, K.W., and Lee, S. (2006) Association study of four polymorphisms in three folate-related enzyme genes with non-obstructive male infertility. Hum. Reprod. 21, 3162-3170.

21. Wang, X., Thomas, P., Xue, J., and Fenech, M. (2004) Folate deficiency induces aneuploidy in human lymphocytes in vitro-evidence using cytokinesis-blocked cells and probes specific for chromosomes 17 and 21. Mutat. Res. 551, 167180.

22. Hobbs, C.A., Sherman, S.L., Yi, P., Hopkins, S.E., Torfs, C.P., Hine, R.J., Pogribna, M., Rozen, R., and James, S.J. (2000) Polymorphisms in genes involved in folate metabolism as maternal risk factors for Down syndrome. Am. $J$. Hum. Genet. 67, 623-630.

23. Bosco, P., Gueant-Rodriguez, R.M., Anello, G., Barone, C., Namour, F., Caraci, F., Roman, A., Romano, C., and Gueant, J.L. (2003) Methionine synthase (MTR) 2756 (A>G) polymorphism, double heterozygosity methionine synthase $2756 \mathrm{AG} /$ methionine synthase reductase (MTRR) $66 \mathrm{AG}$, and elevated homocysteinemia are three risk factors for having a child with Down syndrome. Am. J. Med. Genet. A 121, 219-224.

24. Coppedè, F., Marini, G., Bargagna, S., Stuppia, L., Minichilli, F., Fontana, I., Colognato, R., Astrea, G., Palka, G., and Migliore, L. (2006) Folate gene polymorphisms and the risk of Down syndrome pregnancies in young Italian women. Am. J. Med. Genet. A 140, 1083-1091.

25. Scala, I., Granese, B., Sellitto, M., Salomè, S., Sammartino, A., Pepe, A., Mastroiacovo, P., Sebastio, G., and Andria, G. (2006) Analysis of seven maternal polymorphisms of genes involved in homocysteine/folate metabolism and risk of Down syndrome offspring. Genet. Med. 8, 409-416.

26. Biselli, J.M., Goloni-Bertollo, E.M., Zampieri, B.L., Haddad, R., Eberlin, M.N., and Pavarino-Bertelli, E.C. (2008) Genetic polymorphisms involved in folate metabolism and elevated plasma concentrations of homocysteine: maternal risk factors for Down syndrome in Brazil. Genet. Mol. Res. 7, 33-42.

27. Coppedè, F., Migheli, F., Bargagna, S., Siciliano, G., Antonucci, I., Stuppia, L., Palka, G., and Migliore, L. (2009) Association of maternal polymorphisms in folate metabolizing genes with chromosome damage and risk of Down syndrome offspring. Neurosci. Lett. 449, 15-19.

28. Martínez-Frías, M.L., Pérez, B., Desviat, L.R., Castro, M., Leal, F., Rodríguez, L., Mansilla, E., Martínez-Fernández, M.L., Bermejo, E., Rodríguez-Pinilla, E., Prieto, D., Ugarte, M.; ECEMC Working Group (2006) Maternal polymorphisms 677C-T and 1298A-C of MTHFR, and 66A-G MTRR genes: is there any relationship between polymorphisms of the folate pathway, maternal homocysteine levels, and the risk for having a child with Down syndrome? Am. J. Med. Genet. A 140, 987-997.

29. Patterson, D. (2008) Folate metabolism and the risk of Down syndrome. Downs Syndr. Res. Pract. 12, 93-97.

30. Scala, I., Granese, B., Lisi, A., Mastroiacovo, P., and Andria, G. (2007) Response to "folate gene polymorphisms and the risk of Down syndrome pregnancies in young Italian women" by F. Coppedè et al. (2006). Am. J. Med. Genet. A 143, 1015-1017.

31. Oliveira, K.C., Bianco, B.B., Verreschi, I.T., Guedes, A.D., Galera, B.B., Galera, M.F., Barbosa, C.P., and Lipay, M.V. (2008) Prevalence of the polymorphism MTHFR A1298C and not MTHFR C677T is related to chromosomal aneuploidy in Brazilian Turner Syndrome patients. Arq. Bras. Endocrinol. Metabol. 52, 1374-1381.

32. Hassold, T.J., Burrage, L.C., Chan, E.R., Judis, L.M., Schwartz, S., James, S.J., Jacobs, P.A., and Thomas, N.S. (2001) Maternal folate polymorphisms and the etiology of human nondisjunction. Am. J. Hum. Genet. 69, 434-439.

33. Migliore, L., Boni, G., Bernardini, R., Trippi, F., Colognato, R., Fontana, I., Coppedè, F., and Sbrana, I. (2006) Susceptibility to chromosome malsegregation in lymphocytes of women who had a Down syndrome child in young age. Neurobiol. Aging 27, 710-716.

34. Coppedè, F., Colognato, R., Bonelli, A., Astrea, G., Bargagna, S., Siciliano, G., and Migliore, L. (2007) Polymorphisms in folate and homocysteine metabolizing genes and chromosome damage in mothers of Down syndrome children. Am. J. Med. Genet. A 143, 2006-2015.

35. Petronis, A. (1999) Alzheimer's disease and Down syndrome: from meiosis to dementia. Exp. Neurol. 58, $403-413$. 
36. Schupf, N., Kapell, D., Nightingale, B., Lee, J.H., Mohlenhoff, J., Bewley, S., Ottman, R., and Mayeux, R. (2001) Specificity of the fivefold increase in AD in mothers of adults with Down syndrome. Neurology 57, 979-984.

37. Potter, H. (1991) Alzheimer disease and Down syndrome-chromosome 21 non-disjunction may underlie both disorders. Am. J. Hum. Genet. 48, 1192-1200.

38. Kingsbury, M.A., Yung, Y.C., Peterson, S.E., Westra, J.W., and Chun, J. (2006) Aneuploidy in the normal and diseased brain. Cell. Mol. Life Sci. 63, 2626-2641.

39. Iourov, I.Y., Vorsanova, S.G., Liehr, T., and Yurov, Y.B. (2009) Aneuploidy in the normal, Alzheimer's disease and ataxia-telangiectasia brain: differential expression and pathological meaning. Neurobiol. Dis. 34, 212-220.

40. Ringman, J.M., Rao, P.N., Lu, P.H., and Cederbaum, S. (2008) Mosaicism for trisomy 21 in a patient with youngonset dementia: a case report and brief literature review. Arch. Neurol. 65, 412-415.

41. Beck, J.A., Poulter, M., Campbell, T.A., Uphill, J.B., Adamson, G., Geddes, J.F., Revesz, T., Davis, M.B., Wood, N.W., Collinge, J., and Tabrizi, S.J. (2004) Somatic and germline mosaicism in sporadic early-onset Alzheimer's disease. Hum. Mol. Genet. 13, 1219-1224.

42. Li, J., Xu, M., Zhou, H., Ma, J., and Potter, H. (1997) Alzheimer presenilins in the nuclear membrane, interphase kinetochores, and centrosomes suggest role in chromosome segregation. Cell 90, 917-927.

43. Geller, L.N. and Potter, H. (1999) Chromosome missegregation and trisomy 21 mosaicism in Alzheimer's disease. Neurobiol. Dis. 6, 67-79.

44. Migliore, L., Botto, N., Scarpato, R., Petrozzi, L., Cipriani, G., and Bonuccelli, U. (1999) Preferential occurrence of chromosome 21 malsegregation in peripheral blood lymphocytes of Alzheimer disease patients. Cytogenet. Cell Genet. 87, 41-46.

45. Thomas, P. and Fenech, M. (2008) Chromosome 17 and 21 aneuploidy in buccal cells is increased with ageing and in Alzheimer's disease. Mutagenesis 23, 57-65.

46. Zhu, X., Siedlak, S.L., Wang, Y., Perry, G., Castellani, R.J., Cohen, M.L., and Smith, M.A. (2008) Neuronal binucleation in Alzheimer disease hippocampus. Neuropathol. Appl. Neurobiol. 34, 457-465.

47. Bajić, V.P., Spremo-Potparević, B., Zivković, L, Djelić, N., and Smith, M.A. (2008) Is the time dimension of the cell cycle re-entry in AD regulated by centromere cohesion dynamics? Biosci. Hypotheses 1, 156-161.

48. Zivković, L., Spremo-Potparević, B., Djelić, N., and Bajić, V. (2006) Analysis of premature centromere division (PCD) of the chromosome 18 in peripheral blood lymphocytes in Alzheimer disease patients. Mech. Ageing Dev. 127, 892-896.

49. Spremo-Potparević, B., Zivković, L., Djelić, N., Plećas-Solarović, B., Smith, M.A., and Bajić, V.J. (2008) Premature centromere division of the $\mathrm{X}$ chromosome in neurons in Alzheimer's disease. Neurochemistry 106, 2218-2223.

50. Taupin, P. (2008) Alzheimer's disease, aneuploidy and neurogenesis. Med. Sci. Monit. 14, LE6-6.

51. Coppedè, F. and Migliore, L. (2009) DNA damage and repair in Alzheimer's disease. Curr. Alzheimer Res. 6, $36-47$.

52. Snowdon, D.A., Tully, C.L., Smith, C.D., Riley, K.P., and Markesbery, W.R. (2000) Serum folate and the severity of atrophy of the neocortex in Alzheimer disease: findings from the Nun study. Am. J. Clin. Nutr. 71, 993-998.

53. Ravaglia, G., Forti, P., Maioli, F., Servadei, L., Martelli, M., Brunetti, N., Bastagli, L., Cucinotta, D., and Mariani, E. (2005) Folate, but not homocysteine, predicts the risk of fracture in elderly persons. J. Gerontol. A Biol. Sci. Med. Sci. 60, 1458-1462.

\section{This article should be cited as follows:}

Migliore, L., Migheli, F., and Coppedè, F. (2009) Susceptibility to aneuploidy in young mothers of Down syndrome children. TheScientificWorldJOURNAL 9, 1052-1060. DOI 10.1100/tsw.2009.122. 

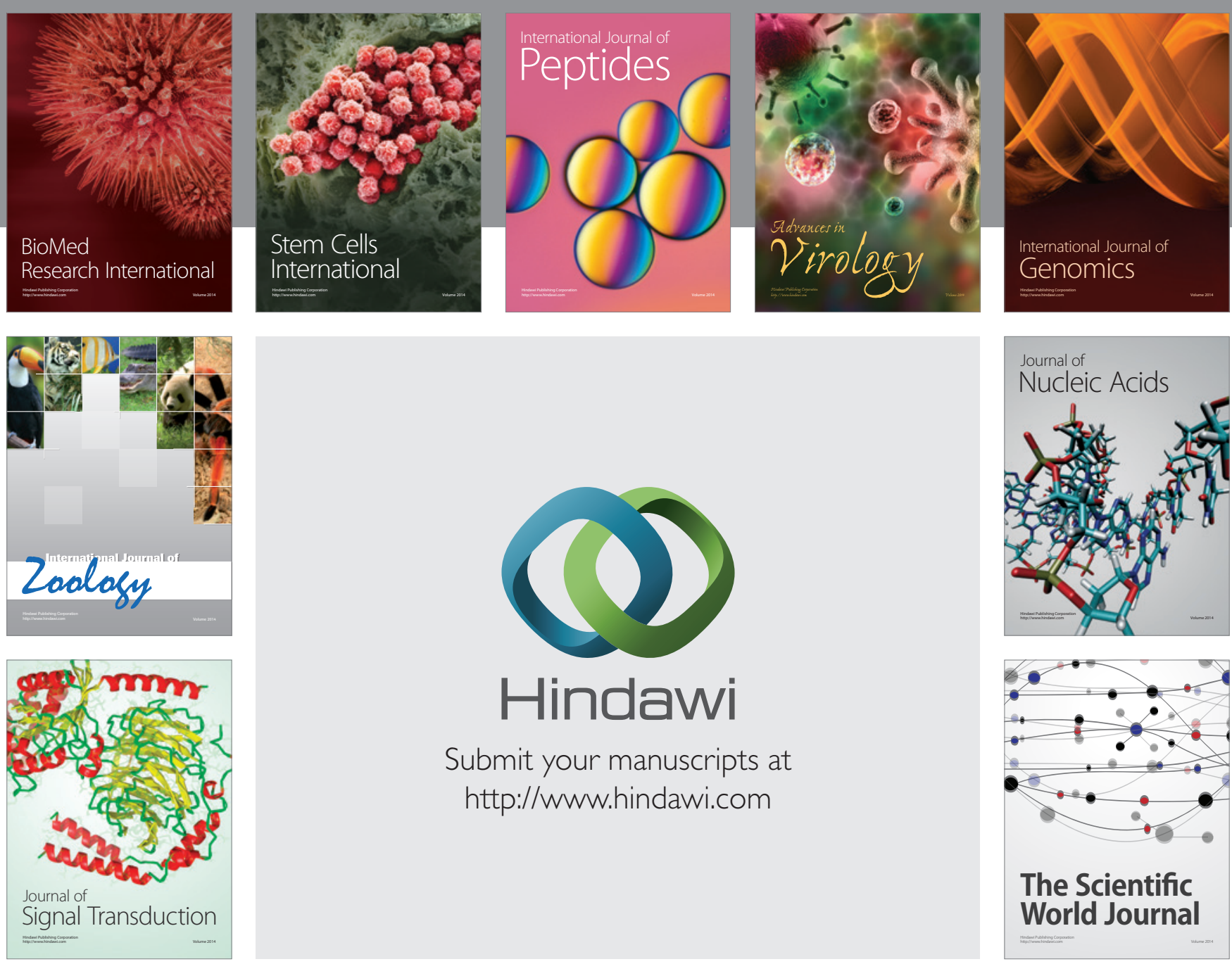

Submit your manuscripts at

http://www.hindawi.com
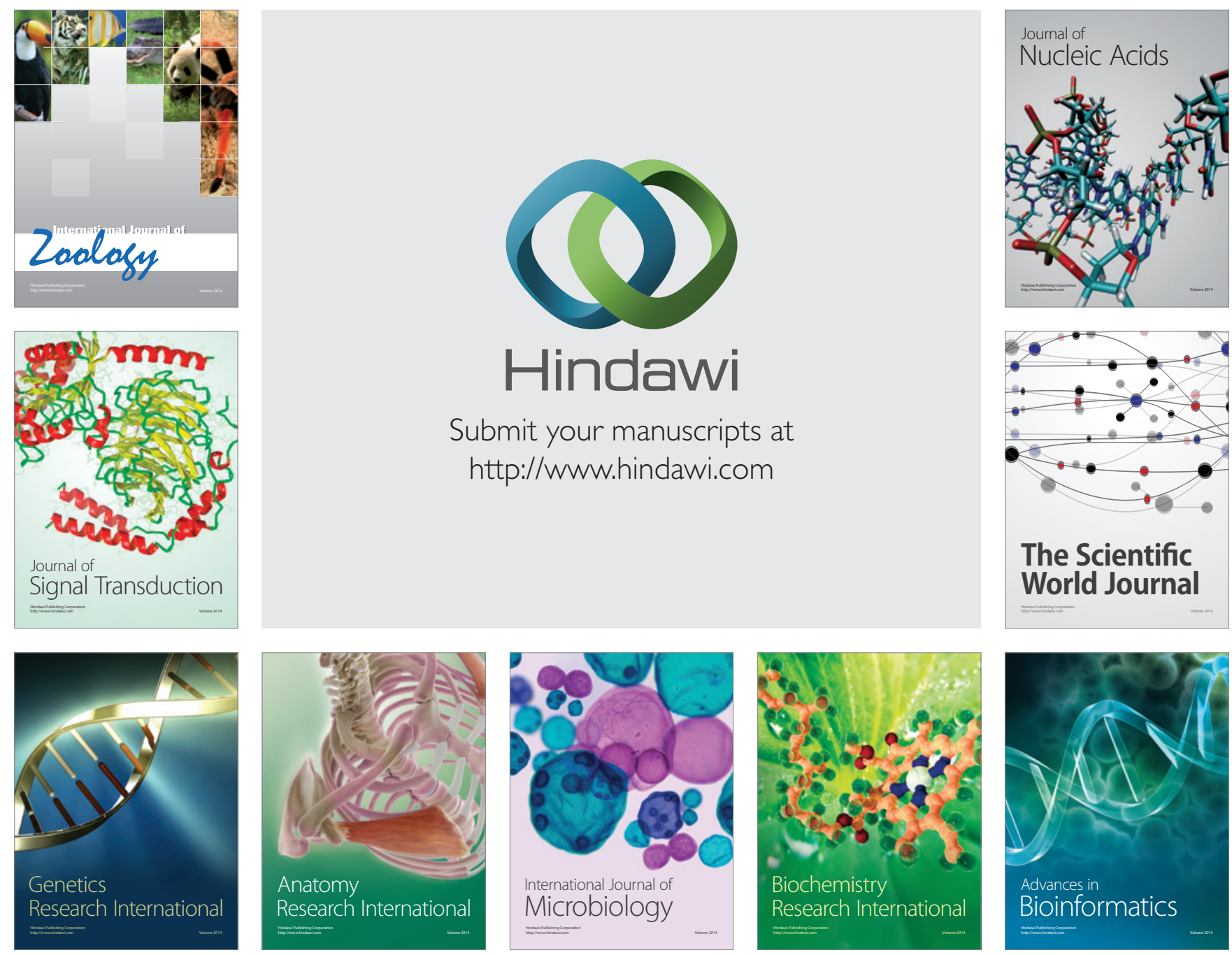

The Scientific World Journal
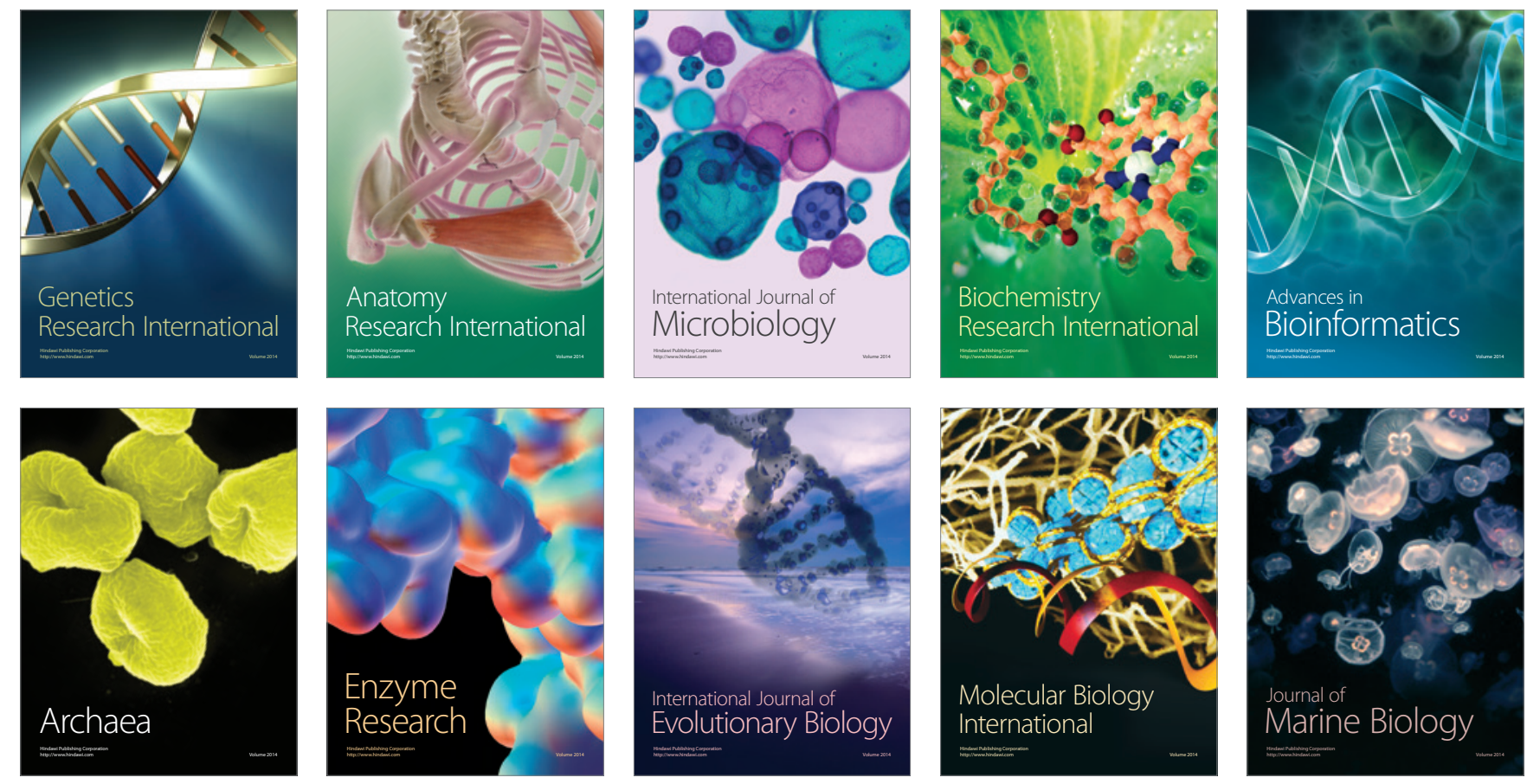